\title{
Herencia de sentimientos en Chile posdictadura*1
}

\section{Legacy of feelings in post-dictatorship Chile}

\author{
Fedra Cuestas*2 \\ Magalí Manzano*3
}

Este artículo propone una reflexión sobre la transmisión de sentimientos entre generaciones como consecuencia de la violencia política. Asentados en el marco de la teoría psicoanalítica, se busca entender la herencia de sentimientos como manifestación de la memoria colectiva en Chile posdictadura.

20 Palabras clave: Herencia de sentimientos, violencia política, memoria colectiva, sentimiento de culpa

${ }^{*}$ El presente artículo se inserta en la continuidad y discusión de los trabajos de investigación de ambas autoras. Si bien, la particularidad del problema a tratar en este texto justifica un artículo específico; debemos mencionar que los resultados aquí presentados se deslindan de aspectos señalados, pero no profundizados en las investigaciones detalladas a continuación. Se agradece a las instituciones que contribuyeron a que nos sigamos planteando nuevas preguntas.

Fedra Cuestas, Duelo y Memoria, Becas Chile - Conicyt, Becas de Post-doctorado en el extranjero - Departamento de Filosofía, Universidad de París VIII, Vincennes - Saint Denis, Francia (2016-2018).

Fedra Cuestas, Deuils publics post-dictature: un travail pour les générations actuelles, Programme de Directeurs d'Etudes Associés de la Fondation Maison des Sciences de l'Homme, Paris, Francia (1/10/2014-10/11/2014)

Magalí Manzano, Tesis de Magister: La autobiografía en el cine documental Chileno, Departamento de Cine, Universidad Paris X Nanterre (2013-2014).

Magalí Manzano, Tesis de Licenciatura: Arte y memoria, Departamento de Filosofía Universidad Paris VIII Vincennes - Saint Denis, Francia (2012).

* 2 Universidad de los Lagos, Sede Osorno (Regións de los Lagos, Chile).

* ${ }_{3}$ Universidad de París 8, Vincennes - Saint Denis (Vincennes - Saint Denis, França). 


\section{ARTIGOS}

\section{Introducción}

\section{La violencia y sus legados}

Intentando explicar el porqué de la guerra, Freud $(1933 / 1986$ e) opone la violencia bruta, que permite el primado del poder del más fuerte; al poder del derecho asentado en la comunidad, que es característico de la cultura y regula la convivencia entre seres humanos. Este último poder también es violento, dado que interfiere en el logro de la satisfacción inmediata e ilimitada de los deseos sexuales y agresivos de los individuos. En "El malestar en la cultura" Freud (1930/1986d) explica las maneras en que el ser humano se relaciona con el malestar causado por la regulación que la cultura establece. Pero las normas que definen la convivencia comunitaria, no siempre son respetadas. Eso sucede cuando, en oposición a la violencia de la regulación de la convivencia social, emerge otra violencia que responde a evadir la limitación que implica el vínculo con otros y a una búsqueda de satisfacción egocéntrica.

El Estado de derecho representa una de las formas en que puede observarse la violencia de la cultura, a él se opone una violencia que promueve el Estado de excepción. En el intersticio de la pugna entre estas formas de violencia, se juega un legado colectivo de sentimientos que puede ser determínate en el devenir de una sociedad.

Un golpe de Estado es una de las formas en que la violencia egocéntrica nombrada anteriormente puede manifestarse al imponerse por la fuerza estableciendo una regulación arbitraria y autorreferente, que no representa ni considera los deseos ni las necesidades del pueblo. Esa violencia, crea o sostiene privilegios, 
que liberan a la minoría dominante de la regulación establecida por la Constitución al permitir que esta sea transgredida durante la vigencia del Estado de excepción. De ese modo, una violencia sin límites queda desatada.

El presente artículo surge dentro del marco del interrogante que nos planteamos respecto al legado que la violencia del Estado de excepción deja en las sociedades. Más precisamente, se busca indagar en la herencia de sentimientos colectivos en Chile posdictadura y las subjetividades que ella construye. Para ello, a partir de una delimitación de los postulados de Freud sobre la memoria de los pueblos (1913/1986c; 1939/1986f), se discrimina a la herencia de sentimientos (1913/1986c) como una forma de expresión de la memoria colectiva, que incide en diversos aspectos de la vida comunitaria. Considerando estudios precedentes realizados en diferentes contextos, se describe el legado de la violencia política, centrándonos en los sentimientos de culpa y vergüenza, para examinar su presencia en descendientes de víctimas y victimarios. A partir de ello, relacionado y distingüendo los contextos considerados, se indaga sobre la herencia de sentimientos en Chile posdictadura, a fin de discernir los sentimientos colectivos que afloran en las generaciones actuales como memoria del pasado dictatorial. La importancia de identificar estos sentimientos, radica en que ellos afectan la convivencia entre ciudadanos, incidiendo en el devenir de la vida comunitaria y el respeto de las formas jurídicas que regulan la cultura.

\section{La herencia de sentimientos}

Si bien Freud (1986a) no dedica ningún texto a trabajar de manera específica lo que él denomina la "memoria de los pueblos", esta problemática atraviesa toda la obra freudiana. Particularmente, en los textos culturales (pero no solo en ellos), el padre del psicoanálisis, se ocupa de pensar una memoria que traspasa los límites de lo individual, lo consciente y las generaciones (Freud, 1986b, VI, Freud, 1913/1986c; Freud, 1939/1986f etc.).

En “Totem y tabú" (Freud, 1913/1986c) y en "Moisés y la religión monoteísta" (Freud, 1939/1986f), esta temática se profundiza en relación a la transmisión intrapsíquica entre generaciones. Para explicarla, el autor oscila entre dos posiciones: la vía ontogenética y la vía filogenética, pareciendo definirse finalmente por esta última.

Estos textos, pueden ser leídos como estableciendo al complejo de Edipo en clave de acceso para entender los problemas de la vida anímica de los 


\section{ARTIGOS}

pueblos, tales como: la religión, la ética, el arte, la política, etc. La memoria no escapa a tal elucidario, ya que el trauma producido por el asesinato del padre primordial, es lo que lleva a Freud a pensar sobre la transmisión de la memoria de los pueblos. Freud construye un mito que hace referencia a un trauma inscripto en la realidad psíquica de cada sujeto que se repite infinitamente en las diversas instituciones sociales. En torno a este mito, delimita una memoria compartida por el pueblo, inconsciente y transgeneracional; a través de la cual los sentimientos de culpa causados por el asesinato del padre persiste en generaciones posteriores sin "saber nada" del acto cometido en los albores míticos de la cultura. Hechos de violencia posteriormente condenados (como Freud ejemplifica mediante el asesinato de Moisés), reactivan la culpa primordial guardada de la memoria de los pueblos a la manera de una herencia arcaica. La memoria inconsciente de la culpa primordial y su reactivación, sostienen y refuerzan la preservación de la Ley.

En el primero de los textos antes citados, Freud (1913/1986c) parte de un paralelismo entre la psicología de los pueblos y la psicología individual, en base al cual supone "una psique de las masas en que los procesos anímicos se consuman como en la vida anímica del individuo" (p. 159). Incluso llega a señalar, que:

Sin el supuesto de una psique de masas, de una continuidad en la vida de sentimientos de los seres humanos que permita superar las interrupciones de los actos anímicos producidos por la muerte de individuos, la psicología de los pueblos no podría existir. (p. 159)

Freud hace una clara hipótesis sobre la existencia de sentimientos colectivos que se transmiten como herencia arcaica a través de las generaciones. Ella contiene una forma de memoria "colectiva". Con este adjetivo se hace referencia a que se trata de una memoria que es compartida por un grupo (familia, comunidad, etnia, humanidad, etc.) Sin embargo, Freud no utiliza ese término, ya que cataloga la memoria que estudia bajo el concepto de memoria de los pueblos. Es de destacar que ella no se corresponde ni al concepto de memoria colectiva en Halbwachs (1991), ni se relaciona con la noción de inconsciente colectivo en Jung (1970).

En torno a la transmisión de la herencia arcaíca, Freud (1913/1986c) se plantea dos cuestiones:

- Conocer el grado de continuidad psíquica que se puede suponer en la serie de las generaciones.

- Identificar los medios y caminos de que se vale una generación para transferir a la que sigue estados psíquicos. 
Freud considera la herencia de predisposiciones psíquicas, señalando que estas, necesitan de enviones para despertar una acción eficaz. Supone que ninguna generación es capaz de ocultar procesos anímicos relevantes a sus descendientes. Refiere una herencia de los sentimientos que seguiría el camino del entendimiento inconsciente. Este camino conduce costumbres, ceremonias, estatutos que se transmiten de una generación a otra, manifestando secuelas del pasado.

Entendemos a esta herencia de sentimientos como una forma de memoria que se actualiza sin necesariamente hacerse memoria consciente. Se trata de una forma de memoria que suele manifestarse en repeticiones visibles al estudiar la historia de los pueblos. Sus expresiones pueden ser observadas en la clínica individual y aparecer en el ámbito privado de la familia. Pero también emergen en la vida pública, llegando a incidir en las modalidades de lazo social y de relaciones de poder que se establecen en una sociedad.

\section{Herencia de sentimientos y violencia política}

Freud describe las secuelas del trauma producido por la violencia ejercida y desencadenada por un padre-autoridad tirano, y la herencia de sentimientos transmitida luego de esas violencias. Del mismo modo, la historia de la humanidad da numerosas muestras de sentimientos legados por una generación a las siguientes como consecuencia de hechos coercitivos que afectaron a una comunidad.

Tal memoria, consecutiva a violencia política, puede encontrarse en la herencia de sentimientos transmitida por los afectados por las guerras, el destierro, los estados de excepción, etc. Al respecto, podemos pensar variados ejemplos: Puede observarse en poblaciones vulnerables afectadas por segregaciones y sometimientos históricos, que heridas actuales reactivan demandas de reparación no proporcionadas a sus ascendientes (Ej: afroamericanos descendientes de esclavos). Del mismo modo, sucede que los descendientes de quienes cometieron abusos contra otros pueblos, se sientan compelidos a reparar los daños realizados por sus antecesores (Ej: jóvenes de países con un pasado colonialista, que destinan su vida a la ayuda humanitaria). Pero también una violencia colectiva traumática que no ha arribado a la consciencia, puede revelar repeticiones aparentemente inexplicables (Ej: neonazis españoles, nietos de españoles que fueron inmigrantes en Alemania, quienes mediante una identificación con el agresor atacan inmigrantes en España). 


\section{ARTIGOS}

En los textos culturales (Freud, 1913/1986c; 1939/1986f), vemos que el sentimiento de culpa se destaca entre la herencia recibida desde los inicios de la cultura. ¿Cómo reaparece este sentimiento frente a la violencia política contemporánea?

\section{Culpa, vergüenza y herencia de sentimientos}

Para Freud, el sentimiento de culpa surge del conflicto que se ocasiona cuando el superyo condena al yo. Ese sentimiento se distingue del temor al castigo. Este último es característico de las primeras etapas de la infancia, anteriores a la instauración del superyo, cuando el castigo es impuesto por los padres y/o autoridades. Posteriormente el superyo toma su relevo condenado al yo y produciendo sentimientos de culpa. Este sentimiento entonces es un residuo del Complejo de Edipo, que recibimos como herencia desde el origen de la cultura.

La culpa, corresponde al sentimiento de haber perdido o haber herido a un objeto de amor. Siendo un sentimiento normal, puede ser distinguido del que aparece en los estados patológicos en los cuales presenta una intensidad desproporcionada.

Pero la culpa no solo surge a causa de la transgresión de una prohibición efectiva. Los fantasmas de tales transgresiones son suficientes para generarla. Tampoco responde solamente a hechos actuales, ya que un sentimiento de culpa originado en un hecho ocurrido en el presente, puede reavivar sentimientos del pasado individual y colectivo.

Es de destacar entonces que, se trata de un estado afectivo que puede ser consciente o inconsciente. Su causa está asentada en la realidad psíquica, puede volverse motivo de necesidad de reparar, o puede llegar a ser promotora de actos destructivos y más precisamente autodestructivos.

El sentimiento de culpa también puede manifestarse en forma de vergüenza. La vergüenza no es un concepto psicoanalítico. Si bien no se trata de un sentimiento particularmente explorado por el psicoanálisis, es observado en la clínica psicoanalítica como síntoma.

Ciccone y Ferrant (2008) relacionan vergüenza y sentimiento de inferioridad. A través de la definición de este último, elaboran una descripción útil para comprender la vergüenza.

El sentimiento de inferioridad es definido, por el Diccionario de Psicoanálisis (Laplanche \& Pontalis, 2004), de la siguiente manera: 
Para Adler, sentimiento basado en una interioridad orgánica efectiva. En el complejo de inferioridad, el individuo intenta compensar, con mayor o menor éxito, su deficiencia. Adler atribuye a este mecanismo una significación etiológica muy general, válida para el conjunto de las afecciones.

Según Freud, el sentimiento de inferioridad no guarda una relación efectiva con una inferioridad orgánica. No constituye un factor etiológico último, sino que debe comprenderse e interpretarse como un síntoma. (p. 398)

Más adelante se aclara que aunque Freud no trató el problema de manera sistemática, hace depender ese sentimiento de dos sufrimientos reales o fantaseados que el niño puede padecer: pérdida de amor y castración.

A continuación se señala lo siguiente:

Estructuralmente, el sentimiento de inferioridad traduciría la tensión existente entre el yo y el superyó que lo condena. Tal explicación subraya el parentesco existente entre el sentimiento de inferioridad y el sentimiento de culpabilidad, pero dificulta su delimitación respectiva.

Después de Freud, varios autores han intentado esta delimitación. D. Lagache hace depender más especialmente el sentimiento de culpabilidad del "sistema Superyó-Ideal del yo", y el sentimiento de inferioridad del Yo Ideal. (p. 399)

Según Ciccone y Ferrant (2008), la vergüenza puede entenderse como una tensión entre el yo y el ideal del yo. El ideal del yo se construye como resultado de la convergencia del narcisismo y las identificaciones a los padres, sus substitutos y los ideales colectivos. La vergüenza muestra el fracaso del yo en relación al ideal del yo. En la vergüenza el yo no ha cometido una falta, pero es indigno.

Siendo que la culpa puede encontrar sus causas en fantasmas, sin necesidad de haber sido ocasionada por una transgresión concretada, que su origen puede remitir al pasado individual y colectivo, esta puede manifestar la memoria de hechos de violencia política que se transmiten como herencia de sentimientos. La vergüenza puede aparecer como manifestación de sentimientos que afectando a una generación son percibidos y entonces heredados por la siguiente. $\mathrm{O}$ bien puede ser la expresión de un conflicto entre valores culturales correspondientes a distintas generaciones.

En los puntos siguientes haremos una revisión de algunas investigaciones sobre la culpa y la vergüenza como legado de la violencia política, a fin de tomarlas como antecedente (considerando la diversidad de contextos socio -históricos), para pensar la herencia de sentimientos en Chile posdictadura. 


\section{ARTIGOS}

\section{Culpa y vergüenza en descendientes de victimarios}

Numerosos testimonios relatan los efectos traumáticos sufridos en las generaciones siguientes de los sobrevivientes de la Shoah (Epstein, 2010). El deber de memoria para con las victimas hace difícil preocuparse por la herencia legada por los victimarios a sus hijos y nietos.

Pensar en los victimarios plantea cuestionamientos. ¿Por qué preguntarse por sus sentimientos? Se hace necesario aclarar que reflexiones de esta índole no implican solidarizar con ellos. Muy por el contrario, se trata de tomar consciencia de quiénes son y qué son capaces de hacer. Por ese medio, se busca evitar la continuidad de sus actos. Además una reflexión sobre la memoria no debería eludirlos en tanto que ellos forman parte de la comunidad que hace memoria y constituye su memoria cultural.

¿Pero es posible ubicar en la misma categoría a los victimarios y a sus descendientes? ¿Se puede pensar un sufrimiento en los descendientes de los victimarios?

En continuidad con los interrogantes que anteceden, Pierre Yves Gaudard (1997) se pregunta si el concepto de dolor solo puede ser aplicado a las víctimas. Propone cuestionar la posibilidad de pensar un sufrimiento que afecta a los verdugos y sus descendientes. Explica que una reflexión sobre ese sufrimiento no implica relativizar el dolor de las víctimas. Constata en jóvenes alemanes, cuyo pasado familiar estuvo involucrado con el nacionalsocialismo, un sufrimiento que afecta las fuentes narcisiticas individuales y genealógicas. Entiende que informar a hijos y nietos de victimarios, las acciones de estos contra las víctimas, implica no olvidar la herencia trágica que recibieron de sus familiares. Esto obliga a llevar una carga de culpa individual y colectiva.

Podemos pensar a partir de allí, que la condena a los culpables de crímenes contra la humanidad, reactiva e intensifica en sus descendientes una culpa contemporánea heredada que repercute sobre la culpa primordial. Esta herencia instaura un conflicto de ambivalencia de sentimientos hacia los padres amados y condenados. Ese conflicto se asienta en la discordancia entre los valores culturales incorporados a través de la identificación con los progenitores y los valores que hoy son apreciados por la cultura a la que pertenecen. Culpa y vergüenza condenan en sí mismo la identificación con figuras relevantes de las generaciones precedentes, en tanto portadores de valores que hicieron posible los crímenes condenados. Pero al mismo tiempo, condenan el hecho de desvalorizar a una figura amada, que fue representante de la autoridad. 


\section{Renegación de la realidad y conflictos en hijos de victimarios}

Durante las dictaduras y/o los gobiernos totalitarios, el criterio de realidad puede ser afectado de manera colectiva. El terror, induce a que una parte importante de la población busque defenderse negándose a ver los crímenes que suceden en su entorno inmediato.

Llegado el fin de estos terribles períodos, cuando una verdad antes oculta se denuncia, muchas personas se sienten culpables de no haber visto, o no haberse dado cuenta de lo que sucedía frente a sus ojos. Pero en el caso de los hijos de los victimarios, la renegación de la realidad no proviene del temor, sino del conflicto producido entre el sentimiento de amor hacia sus padres y la reprobación a los crímenes que ellos cometieron. Las denuncias no cambian este conflicto, más bien lo instauran o intensifican, razón por la cual suele ocurrir que estos jóvenes (a diferencia de gran parte de la población) continúen recurriendo al mecanismo de la negación.

Cuando mediante la confesión (como en el caso de Sudáfrica), o a través de los dictámenes de juzgados nacionales (Ej. Argentina) y/o internacionales (Alemania posguerra), es posible comprobar y condenar crímenes contra la humanidad, para los descendientes de quienes los cometieron, se vuelve muy difícil continuar empleando el mismo mecanismo de defensa. Entonces, su conflicto puede hacerse más acuciante. Aceptar el amor de hijo, conlleva un sentimiento de complicidad respecto a los crímenes cometidos, lo cual conduce a un sentimiento de culpabilidad. Rechazar ese amor conduce al mismo destino marcado por la culpa. Pero el sentimiento de culpa puede aparecer en la consciencia, o permanecer inconsciente.

La condena de los actos cometidos, suele manifestarse también a través de un sentimiento de vergüenza. Tal como ya se había explicado, el ideal del yo no se forma solamente por identificaciones a los padres idealizados, también los ideales culturales lo constituyen. En situaciones de abruptos cambios históricos o culturales (migraciones, dominación cultural, revoluciones, pasaje de una dictadura a la democracia o viceversa) hay divergencias entre los ideales culturales que corresponden a cada generación. La generación de los hijos de victimarios puede incorporar ideales culturales muy diferentes a los de sus padres. ${ }^{1}$ En ese caso, se crea un conflicto entre el yo y el ideal del yo, produciendo la vergüenza. Ese sentimiento debate un conflicto entre modelos de identificación. La identificación a los padres constituye una afrenta a la identificación con los ideales colectivos, como consecuencia el yo se siente indigno. 


\section{ARTIGOS}

Investigaciones recientes en Alemania (Moller et al., 2013) muestran que la memoria familiar del período nazi puede entrar en contradicción con la memoria comunicativa. Mientras que se reconocen los crímenes cometidos por Alemania, un importante porcentaje de alemanes niega la existencia de miembros de su familia implicados en el pasado criminal de su país. El éxito en la transmisión a los jóvenes actuales de los horrores cometidos en las generaciones precedentes, produce nuevas negaciones al interior de la memoria familiar. Aparentemente estos resultados podrían contrastar con lo señalado por Gaudard (1997). Sin embargo, siendo que la condena social a los crímenes cometidos permanece intacta, se puede pensar que el conflicto identificatorio antes mencionado, es evadido por medio de mecanismos de defensa que deformado la memoria familiar, niegan la participación de familiares cercanos en los crímenes penados. Queda por indagar la evolución de este conflicto que hoy permanece latente.

Pero culpa y vergüenza, no solo recuerdan los crímenes fratricidas cometidos por quienes ocuparon el estatuto de padres (autoridades del Estado, generaciones precedentes: padres, abuelos, tíos, maestros, etc.), sino que también remiten a una culpa de antaño referida al asesinato del padre de la Horda primitiva. La culpa proveniente de los inicios de la cultura se reactualiza frente a la condena que pesa sobre el padre fundador de la propia familia, los padres de familias del entorno, los padres simbólicos autoridades del entorno, los padres-autoridades del Estado. Todos ellos son destituidos de su lugar al ser desautorizados por la condena. El desprecio por los criminales de la generación precedente, puede acarrear vergüenza, si hubo antes una identificación a su investidura (Mitscherlich, 1972). La figura del dictador destituido, pero antes fuertemente amado u odiado, conlleva sentimientos de culpa procedentes de los deseos de muerte dirigidos hacia él. De esta manera, recae sobre las nuevas generaciones (y no solo sobre los descendientes directos de los criminales), una culpa recibida como herencia tal como se observa en el estudio de Gaudard (1997) antes citado.

Esos sentimientos remiten a otros iniciados al paso de la cultura a causa de los deseos de muerte hacia las figuras paternas que detentan poder y limitan las satisfacciones. Ahora bien, la aparición de sentimientos de vergüenza o de culpa en generaciones posteriores a las que cometieron o

${ }^{1}$ En Argentina integrantes del colectivo Historias desobedientes, formado por hijas e hijos de genocidas, denuncian y reclaman condenas para sus progenitores. 
apoyaron la violencia de Estado, siempre tiene como premisa una condena social que permita transmitir una memoria que desapruebe un pasado del cual se recuerdan atentados contra la comunidad. Para que se reaviven sentimientos de estar en falta ante la ley, es necesario que la ley se reestablezca y condene a quien la quebrantó.

\section{Criterio de realidad y condenas en Chile posdictadura}

En Chile, los acuerdos realizados por la transición democrática orientaron las políticas de perdón y reconciliación hacia abusos del olvido. Un gran impulso a la recuperación del criterio de realidad colectivo fue dado gracias la causa promovida por el Juez Garzón, que permitió el arresto del dictador chileno en Londres. La sanción internacional no pudo ser totalmente renegada. Pero posteriormente la insuficiencia de veredictos públicos en suelo chileno, no da lugar a una verdadera condena social. Si bien han habido sentencias que incriminan a algunos culpables por las violaciones contra los derechos humanos perpetrados durante la última dictadura, no hay divulgación de las mismas. Tampoco hay suficientes instancias de reconocimiento y reparación a las víctimas. Todo ello, no favorece la asunción de culpas ni en victimarios, ni en las generaciones siguientes.

De lo explicado en el punto anterior, es necesario destacar el papel fundamental que juega el reconocimiento de la verdad para finalizar un período de violencia política y establecer una convivencia donde imperen los valores que sustentan los derechos humanos. Las confesiones o las condenas judiciales, permiten a las víctimas ser reconocidas en su estatuto, para así poder dejar ese lugar y convertirse en sobrevivientes. Pero fundamentalmente, al mismo tiempo, reinstauraran en toda la sociedad el criterio de realidad que había sido distorsionado durante el período en que los crímenes eran negados. Ahora bien, a tal fin, es indispensable que esas condenas sean públicas. Una condena judicial que confirme la autoría de los crímenes adjudicados a los victimarios, permite que la sociedad tome conciencia de aquello que había reprimido a causa del terror. La condena judicial difundida en la sociedad, y como efecto de esta, la condena social generalizada a los crímenes cometidos por generaciones predecesoras (a la cual pertenecen padres y/o abuelos), es absolutamente indispensable para un cambio cultural que asiente los valores democráticos. 


\section{ARTIGOS}

Pero, ¿Qué sucede cuando esta condena no se produce? Bajo la ausencia de tal condena no puede aparecer el conflicto antes mencionado. Cuando los ideales culturales no condenan y por ello no desautorizan crímenes ni criminales, las generaciones siguientes, aun siendo conscientes de la implicación de sus antecesores en crímenes de lesa humanidad, pueden llegar hasta a reivindicar y honrar a los verdugos a causa de los hechos por ellos cometidos. En tal caso, no hay sentimientos de culpa, ni conflictos; solo resta la compulsión a la repetición que se manifiesta en reiteración de una violencia no tramitada.

\section{Culpa y vergüenza en Chile post-dictadura}

Los pactos de olvido llevan a que en ocasiones sean los hijos de las víctimas quienes sientan vergüenza de su historia familiar. Un consenso generalizado desaprueba hablar sobre el pasado que se fuerza a olvidar. Las víctimas repiten su condición al aparecer como socialmente cuestionables por portar su verdad, incluso en ocasiones hasta ante sus propios descendientes. Los descendientes de víctimas no pueden posicionarse como tales, sin ser revictimizados con una condena social que pesa sobre ellos, por el hecho de ser la manifestación de una verdad que no toda la sociedad está en condiciones de escuchar.

No son los descendientes de victimarios quienes sienten vergüenza de su pasado familiar, sino los de las víctimas. Son estos últimos quienes viven un conflicto entre los ideales incorporados de su cultura y los ideales transmitidos por su entorno familiar. No estando sancionados los victimarios, ni comprobados públicamente los crímenes que cometieron, permanece vigente un discurso social de reprobación hacia las víctimas. Y justamente son sus ideales lo que una parte importante de la sociedad desaprueba. Para muchos jóvenes descendientes de víctimas, la identificación con los ideales de sus familiares y/o la reivindicación del estatuto de víctima, conlleva el costo de una desautorización social. Ello les abre dos caminos igualmente violentos: aceptar autocensurase o ser objeto de marginalización. Como consecuencia de ello pueden llegar a volverse contra sus padres, esgrimiendo discursos semejantes a los de los victimarios.

A los pactos del olvido, se suma el olvido producido por el trauma y el temor a sus consecuencias. Las víctimas suelen ocultar a sus hijos su condición 
por temor a hacerles daño con el relato de lo que han sufrido. Sin embargo, los sentimientos de las víctimas y las marcas que en ellos dejó la violencia política no pueden ser ocultados a su descendencia. Esto refuerza el sentimiento de vergüenza en los descendientes de las víctimas. Por un lado, el desconocimiento de la historia familiar no da lugar a que los descendientes de víctimas cuenten con recursos ante los cuestionamientos a la verdad, y puedan integrar su pasado contrargumentando la versión aún vigente del discurso social que reniega una historia de violencia fraticida y esgrime la inexistencia de víctimas. Por otra parte, el silencio sobre el pasado sufrido, no impide que los padres sobrevivientes transmitan a sus hijos el sentimiento de vergüenza que ellos portan a causa de la deshumanización sufrida (tortura, vejaciones, etc.). Esa vergüenza callada de las víctimas, es percibida y transmitida por entendimiento inconsciente, siendo recibida e incorporada por los hijos sin poder ser elaborada.

Las víctimas y sus familiares necesitan del reconocimiento social. Este reconocimiento, en sí mismo, es un acto reparatorio, en la medida que devuelve el valor humano a quienes fueron deshumanizados por sus victimarios. En tanto prime el olvido, la intención de los victimarios de borrar la existencia de desaparecidos y sobrevientes permanece lograda. La ausencia de reconocimiento hace imposible el deber de memoria para con las víctimas.

En Chile, la vergüenza entonces es el síntoma de la revictimización de los sobrevivientes y sus familiares. En tanto, el sentimiento de culpa se torna en el gran ausente. Ausencia de verdadera importancia para el devenir de la democracia, ya que sin condena a los culpables, sin reconocimiento de una culpa reciente, sin reactivación de la culpa primordial; no cabe esperar un integro restablecimiento del orden jurídico quebrantado por el golpe de Estado.

\section{Herencia de sentimientos en Chile post-dictadura}

Considerando lo antes explicitado, es necesario preguntarse: ¿Cuál es la herencia de sentimientos legada a las generaciones actuales en Chile posdictadura?

Observando la relevancia que han tomado en los últimos tiempos los sentimientos de impunidad e inseguridad, proponemos que ellos contienen la memoria del pasado reciente. La arbitraiedad y el terror de la última dictadura generaron y mantuvieron esos sentimientos desconectados de la consciencia. Posteriormente, la ínfima condena social a los culpables de crímenes efectuados durante el Estado de excepción, reforzó los mismos sentimientos. 


\section{ARTIGOS}

Ellos solo pudieron aflorar a la consciencia luego de haber sido transmitidos a las generaciones de hijos y nietos de víctimas y victimarios, quienes los proyectan sobre otros delincuentes, manteniendo la impunidad de quienes cometieron violencia de Estado.

Por una parte, la indolencia en la reprobación ante crímenes contra la humanidad, dio paso a una impunidad frente a otros delitos. De ese modo se instauró un clima de aparente impunidad generalizada que permite constantes infracciones contra las normas, haciendo que se extienda una corrupción que abarca los más diversos espacios sociales. La contravención de la ley iniciada con el no respeto de la Constitución instaurado por golpe de Estado, se reitera aún hoy de manera cotidiana en pequeños y grandes hechos que aplican la ley de modo arbitrario. Ello instala una violencia concomitante que escala. En este clima y al interior de una frágil democracia, tal como lo expresa Agamben (1997, 2003, etc.), el Estado de excepción gana terreno tendiendo a volverse permanente.

Como contraparte, se manifiesta frecuentemente una sensación de inseguridad, efecto inmediato de la arbitrariedad y la imprevisibilidad que se corresponden a la corrupción. Aparentemente la inseguridad, responde a un clima de no castigo a delitos privados (contra la propiedad, violencia intrafamiliar, etc.). Sin embargo, es necesario pensar que detrás de estos delitos asechan los recuerdos reprimidos de una violencia política culpable de crímenes contra la humanidad.

La inseguridad remite al terror de un pasado en el que la amenaza contra la vida era un contenido preconsciente constante para toda la población. La impunidad proviene de la ausencia de condena a quienes originaron ese terror.

La demanda frente a esta sensación de inseguridad heredada y perpetuada, no plantea una reflexión sobre sus causas, ni propone medidas que tiendan a cambios sociales. Más bien hay una exigencia de incrementar la represión, lo cual da muestras de una violencia traumática no elaborada que se repite compulsivamente.

Violencia contra violencia. Violencia que exige más violencia. Pero solo violencia por la fuerza, violencia bruta, que cuestiona las leyes y apela a la coerción. Violencia que surge de evitar enfrentar el conflicto que entraña todo pasado, de evadir hacer memoria y responder al deber de memoria. Violencia destructiva que se opone al trabajo de la cultura.

Para Ricœur (2010) el deber de memoria es un imperativo de justicia que se impone como obligación. Ese deber es una deuda hacia las víctimas. Saldar esa deuda implicaría reconocerse en tanto sociedad como herederos de victimarios, y otorgar una reparación a las víctimas. Una sociedad que evade el 
conflicto que la lleve a asumir su culpa y entonces poder repararla, no puede hacer un trabajo de memoria que le permita elaborar su pasado. La carencia de una memoria consciente que reactive conflictos y sentimientos de culpa, se traduce en otra forma de memoria que es herencia de sentimientos. Esta memoria no consciente se manifiesta como repetición que actúa el pasado.

Las políticas del olvido, que intentan evadir conflictos y aplacar sentimientos de culpa por los crímenes cometidos en el pasado reciente, al no reactivar la culpa primordial, no logran sustentar la ley que regula la vida comunitaria. La corrupción se extiende, ofreciendo excusas a quienes vuelven a invocar la violencia de Estado. Las actuales demandas de control represivo frente a los sentimientos de impunidad e inseguridad heredados, no son más que una memoria que se manifiesta como compulsión a la repetición.

\section{Referencias}

Agamben, G. (1997). Homo sacer. Le pouvoir souverain et la vie nue. Paris, France: Éditions du Seuil.

Agamben, G. (2003). Etat d'exception. Homo sacer. Paris, France: Éditions du Seuil.

Ciccone, A., \& Ferrant, A. (2008). Honte, culpabilité et traumatisme. Paris, France: Dunod. Epstein, H. (2010). Le traumatisme en héritage. Paris, France: Gallimard.

Freud, S. (1986a). Sigmund Freud Obras completas. Buenos Aires, Argentina: Amorrortu.

Freud, S. (1986b). Psicopatología de la vida cotidiana. In Sigmund Freud Obras completas (Vol. VI). Buenos Aires, Argentina: Amorrortu. (Trabajo original publicado en 1901).

Freud, S. (1986c). Tótem y tabú. In Sigmund Freud Obras completas (Vol. XIII). Buenos Aires, Argentina: Amorrortu. (Trabajo original publicado en 1913).

Freud, S. (1986d). El malestar en la cultura. In Sigmund Freud Obras completas (Vol. XXI). Buenos Aires, Argentina: Amorrortu. (Trabajo original publicado en 1930).

Freud, S. (1986e). ¿Por qué la Guerra? In Sigmund Freud Obras completas (Vol. XXII). Buenos Aires, Argentina: Amorrortu. (Trabajo original publicado en 1933).

Freud, S. (1986f). Moisés y la religión monoteísta. In Sigmund Freud Obras completas. (Vol. XXIII). Buenos Aires, Argentina: Amorrortu. (Trabajo original publicado en 1939).

Gaudard, P I. (1997). Le fardeau de la mémoire. Paris, France: Plon.

Halbwachs, M. (1991). La mémoire collective. Paris, França: Éditions Albin Michel. 


\section{ARTIGOS}

Jung, K G. (1970). Arquetipos e inconsciente colectivo. Barcelona, España: Paidós.

Laplanche, J., \& Pontalis, J-B. (2004). Diccionario de psicoanálisis. Barcelona, España: Paidos.

Mitscherlich A., \& Mitscherlich M. (1972). Le deuil impossible. Paris, França: Payot.

Moller, S. et al. (2013). «Grand-père n'étais pas un nazi» National-socialisme et Shoah dans la mémoire familiale. Paris: France: Éditions Gallimard.

Ricœur, P. (2010). La memoria, la historia, el olvido. Buenos Aires, Argentina: Fondo de Cultura Económica.

\section{Resumenes}

(Herança de sentimentos no Chile pós-ditadura)

Este artigo propõe uma reflexão sobre a transmissão de sentimentos entre gerações como consequência da violência política. Assentado no marco da teoria psicanalítica, o artigo procura entender a herança de sentimentos como manifestação da memória coletiva no Chile pós-ditadura.

Palavras-chave: Herança de sentimentos, violência política, memória coletiva, sentimento de culpa

\section{(Legacy of feelings in post-dictatorship Chile)}

This paper proposes a reflection on the transmission of feelings from one generation to another as a consequence of political violence. Based on the approaches of the psychoanalytic theory, this paper aims to understand the legacy of feelings as a manifestation of the collective memory in post-dictatorship Chile.

Key words: Legacy of feelings, political violence, collective memory, sense of guilt

(Héritage de sentiments au Chili post dictature)

Cet article propose une réflexion sur la transmission de sentiments à travers les générations comme conséquence de la violence politique. À l'aide de la théorie psychanalytique, on cherche à comprendre l'héritage de sentiments comme manifestation de la mémoire collective au Chili post-dictature.

Mots clés: Héritage de sentiments, violence politique, mémoire collective, sentiment de culpabilité

(Gefühlserbschaft in Chile nach der Diktatur)

Der vorliegende Artikel soll dazu dienen, Denkanstöße über die Folgen der politischen Gewalt und die daraus resultierende, generationsübergreifende Gefühlsübertragung zu liefern. Aus der Sicht der psychoanalytischen Theorie soll 
versucht werden, die Gefühlserbschaft zu verstehen, und zwar als Ausdrucksform eines Kollektiv-gedächtnisses im heutigen Chile.

Schlüsselwörter: Gefühlserbschaft, Politische Gewalt, Kollektivgedächtnis, Schuldgefühl

Citação/Citation: Cuestas, F., \& Manzano, M. (2019, março). Herencia de sentimientos en Chile posdictadura. Revista Latinoamericana de Psicopatologia Fundamental, 22(1), 20-37. http://dx.doi.org/10.1590/1415-4714.2018v22n1p20.2.

Editora da entrevista/Editor: Profa. Dra. Ana Maria G. R. Oda e Profa. Dra. Sonia Leite

Recebido/Received: 1.4.2018 / 4.1.2018 Aceito/Accepted: 28.1.2019 / 1.28.2018

Copyright: (C) 2009 Associação Universitária de Pesquisa em Psicopatologia Fundamental/ University Association for Research in Fundamental Psychopathology. Este é um artigo de livre acesso, que permite uso irrestrito, distribuição e reprodução em qualquer meio, desde que o autor e a fonte sejam citados / This is an open-access article, which permits unrestricted use, distribution, and reproduction in any medium, provided the original authors and sources are credited. 


\section{ARTIGOS}

Financiamento/Funding: Este trabalho não recebeu financiamento / This work received no funding.

Conflito de interesses/Conflict of interest: Os autores declaram que não há conflito de interesses / The authors declare that there is no conflict of interest.

\section{Fedra Cuestas}

Dra. en Filosofía, Universidad de París 8, Vincennes - Saint Denis (Saint Denis, France); Prof. Departamento de Ciencias Sociales, Universidad de los Lagos, Campus Osorno (Région de los Lagos, Chile);

Av Alberto Fuchslocher 1305

Osorno, Región de los Lagos, Chile

https://orcid.org/0000-0001-5058-6546

fedracuestas@hotmail.com

\section{Magalí Manzano}

Lic. En Filosofía, Universidad de París 8, Vincennes - Saint Denis (Saint Denis, France); Mag. en Cine, Universidad de París X Nanterre (Paris, France).

https://orcid.org/0000-0003-2397-1566

magalimanzanocuestas@gmail.com

This is an open-access article, which permits unrestricted use, distribution, the original authors and sources are credited. 